\title{
Industry 4.0 and metrology centres
}

\author{
José Luis Prieto ${ }^{1, *}$ \\ ${ }^{1}$ Interim Manager, 32005 Ourense, Spain
}

\begin{abstract}
Historically laboratories/metrology centres have considered the management aspects of their respective organizations in a somewhat collateral manner, putting all their emphasis on the technical aspects. The editions of the international standards that have sustained and supported the accreditation processes have been giving greater importance to these aspects of management. The ongoing revision of ISO 17025 indicates its most significant changes towards them. And if the regulatory environment is boiling, what about the socio-economic one! Industry 4.0 together with the digital transformation will influence all types of organizations, and laboratories/metrology centres cannot be alien to the challenges they face with. The transversality of the science of measurement, that it is to say, metrology, makes it relevant but not stellar in each and every one of the aspects to which this revolution is directed. Let's not forget that governments and scientists are calling it Fourth Industrial Revolution. This paper focuses on the challenges that must be faced from these laboratories/metrology centres to key points of clearly organizational influence such as innovation, entrepreneurship and/or conversion to customer-centric organizations.
\end{abstract}

\section{Metrology centre: a definition in terms of knowledge}

The hallmark of metrology centres is knowledge. Regardless of whether they are entities for or not for profit, or the dominant metrology scope in their activities (industrial, legal or scientific), they are entities that walk from the production and co-generation of knowledge to their dissemination and transfer.

Knowledge is both their main input and output and their primary value-added activities consist of the creation, accumulation and dissemination of knowledge for the purposed of developing customised service solutions.

For defining a general knowledge value chain, the distinguishing exploration-examination-exploitation is considered as the dynamic element that describes the enhancement and processing of knowledge units on the way towards their transformation into commercially valuable knowledge products.

Two dimensions of knowledge, y-axis named as Categories (analytical, synthetic and symbolic) and $\mathrm{x}-$ axis named as Phases (exploration, examination and exploitation) (see Fig.1) to properly position their way of acting.

Vertical and horizontal knowledge domains reinforce their goal for growth and sustainability combining business functions with transversality of metrology (visible in any sector either industrial or services).

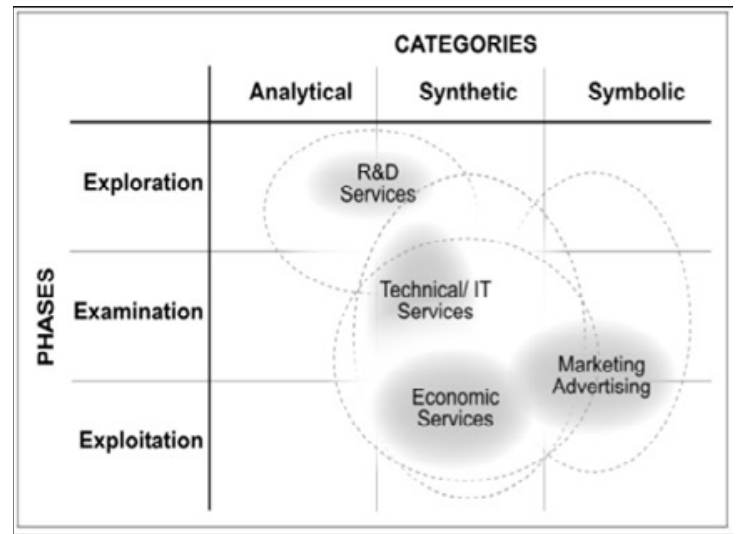

Fig.1 Focus on the knowledge basis and phases on the knowledge value chain. Source [1]: Strambach (2008)

\section{Opportunities from ISO/IEC 17025}

This hatching in the most remote environment coincides with renewal airs in the nearest and direct environment, as is represented by the accreditation, in terms of the regulation that addresses the same for this typology of entities that concerns us and concerns.

One of the non-negotiable requirements during this process, up to the present moment, is that the high-level structure has been adopted as a common framework for all those rules that articulate management systems, either generic or non-negotiable. Specific areas of organizational management, as is the case in particular, ISO 17025 [2].

\footnotetext{
* Corresponding author: jotaelepece@gmail.com
}

(C) The Authors, published by EDP Sciences. This is an open access article distributed under the terms of the Creative Commons Attribution 

things:

This step is pursued in general terms, among other -Establish aligned policies and objectives in overall strategic planning.

- Optimize the allocation of resources.

- Joining the documentary system and certain processes. -Manage improvement initiatives, with common approaches.

-Address conformity assessment in an integrated manner

The approach to improvement initiatives broadens the horizon by considering not only risk-based thinking, already implicit in the version still in force in 2005, for example through preventive actions to eliminate potential nonconformities, or to analyze any nonconformity that occurs, And take actions that are appropriate for the effects of nonconformity in preventing their recurrence, but expanding their orientation when planning and implementing actions to address opportunities.

Opportunities that can arise as a result of a favorable situation to achieve an expected result, for example, a set of circumstances that allows the organization to attract customers, develop new products and services or expand the scope of laboratory activities.

\section{Industry 4.0 and its levers}

The availability of digital information, process automation, the interconnection of the value chain and the creation of digital interfaces with the consumer act as levers of digital transformation that are redefining business models and reorganizing industries.

So, the following levers are defined:

- Digital information: the capture, processing and analysis of digital information enables improved predictions and decision making - Automation: the combination of traditional technology and artificial intelligence generates systems that can work autonomously and organize themselves (reducing errors, acting faster and cutting operating costs) - Connectivity: the interconnection of the entire value chain via mobile or broadband allows synchronization of logistics chains, shorten delivery times and innovation cycles.

- Digital access to the customer: internet (mobile and high speed) allows new intermediaries to target consumers who can offer total transparency and new services.

\section{Organizational challenging mix for metrology centres}

The challenges are not only to predict the implications of the technologies around Industry 4.0 but to create new types of organizations and business models that take advantage of the technological possibilities that we have today.

Understanding the changes brought about by the technological revolution and adapting to them the business models of companies is fundamental to develop the potential opportunities of the new environment and minimize their threats. The change must be constant, coherent, patient and focused

The new models require greater customer participation, greater agility and the development of continuous innovation processes.

Recurring archetypes in most business models: - Firstly, the one based on customer proximity, which uses customer information to offer tailor made solutions for very specific needs and to meet customers' tastes and habits to ensure a personalized and high quality service experience.

- Secondly, it is based on operational excellence, when the objective is to minimize the final cost of the product or service; so that competitive prices can be offered thanks to the reduction of intangible costs to the customer when making the delivery, This way, the excellence of operations is not only focused on the price, but on the guarantee of the service. - The third is focused on the coordination of the value chain, creating value through the synchronization of the initial and final ends of the value chain

\subsection{Innovation}

The introduction of new technologies positions the organizations before a complex network of opportunities and challenges that generate changes in the management practices and favor the appearance of new organizational forms.

An innovative entity aims to transform technological and market constraints by developing distinctive organizational capabilities that competitors cannot easily imitate.

The basic challenge of an innovative entity is to evolve towards an ambidextrous organization, maintaining the balance between exploitation and exploration or between stability and change and, in addition, constantly coordinating the two aspects in a dynamic way.

The double quest for stability and change is a fundamental paradox in all forms of organization and poses a major challenge to firms operating in today's business environment.

Exploitation extends existing knowledge while exploration requires the creation of new knowledge and ideas. In any case, the key to a company's long-term success lies in its ability to exploit existing skills while continuing to explore new possibilities, in order to compete in both mature and emerging markets.

\subsection{Entrepreneurship}

For decades, scale and size have been desirable traits in a company. In this new panorama drawn by the Fourth Industrial Revolution, adaptability and agility will eclipse them more and more.

The venture is attributed to organizations that create favorable environments or spaces to which new lines of services or improvements are added to existing ones, that promote acquisitions or that stimulate R \& D 
through the development of entrepreneurial talent from within the organization.

The information flow is needed in a constructive way to enable decision making to facilitate the adoption of initiatives aligned with a broad and multidisciplinary vision and to strengthen the confluence of workers' values and organization

The distance between information and decision making results in the following structural failures: - Information progresses slowly and knowledge takes a long time to implement.

- Reality is distorted at each point of transmission. - The information flow pattern inevitably gives way to a tremendous amount of intelligence and intermediate experience.

- The process often causes organizations to behave in a sociopathic way, since it ultimately forces employees to do things against their best judgment

The solution is to find a border, take advantage of the data to scale rapidly and become a new core business.

The evolution towards the entrepreneurial organization takes as factors to handle the following: Resources, Attitudes and Skills. Otherwise you can talk about these factors as POWER (Resources), WANT (Attitudes) and KNOW (Skills).

The evolutionary movement has to take into account the starting point, in a trihedron that is defined by these three vectors.

In the case of laboratories / metrology centers, these are mostly in the area of Resources (POWER) Skills (KNOW), so the challenges in this new environment must focus on gaining depth in the vector Attitudes (WANT).

Within the field at hand, the following evolutionary pathways can be identified in general: -Studying new ideas, valuing them, contributing existing knowledge within the entity and investing in them - Rethinking how to act (through professional enrichment and personal empowerment), still lacking the resources to take advantage of missed opportunities. - Find another entity in the ecosystem that has the resources and attitude to offer its own knowledge and associate

The desired ideal position must result from combining all three factors into dimension sufficient to be recognized within the value ecosystem.

Competition at the global level leads each individual within his or her organization to assume its leading role in the development of its future.

\subsection{Customer-centric}

Digital uses of consumers transform demand, which for companies means re-positioning the final consumer in the "centre" of their development logic, for example by increasing the value proposition to the customer with greater reactivity, personalized attention or quality of superior service.

This strategy fundamentally aligns the company's products and services with the desires and needs of its most valuable customers, with the specific objective of obtaining greater profits over a longer period of time.

The well-being of the clients has to be known, via metrics and panels of the client, by all levels of the organization including the meetings of the senior management.

The maximum of action tries to reduce distance with the client. For this, all the staff is invited to participate to improve the customer experience, as this is not only a task of customer service.

Most valuable clients and clients with a long-term relationship with the company are recognized, rewarded and treated so that the appreciation for their loyalty is clearly demonstrated.

Clients are invited to provide new insights and to join the organization, through their participation in councils and client groups.

Reinforcement of the focus on the client to anticipate and respond to their needs and habits, reactivity, personalized attention and quality of service, interactive approach with the community of customers are ways of action to achieve customer-centric organization.

Similarly, digitization provides solutions, for example by creating direct contact between producers and final consumers, complementing distributors. It also helps to renew products, through "connected objects", mass customization or online services.

Business ecosystems are more than just one of the organizational formulas of the digital economy. Its philosophy of cooperation represents one of the central visions of the digital economy.

These are achieved through the creation of collaborative environments not only within the company itself, but with the outside: partners, partners, suppliers, customers and even the competition itself.

All interact with each other and with their environment, thus maintaining the balance of the system and seeking to ensure the survival.

\section{Conclusions}

Industry 4.0 could truly transform the way companies, and metrology centres as well, operate and enable them to tap into new sources of value.

To achieve this transformation, companies follow a set of imperatives:

- Gain an in.depth understanding of how Industry 4.0 can create value in the specific context of your operations. Identify ways to reach the next frontier of value creation instead of pursuing incremental improvements.

- $\quad$ Articulate a bold vision for how you will apply digital technologies, and establish ambitious, stepchange objectives across the organization. Independent initiatives scattered throughout the company, without clear vision and coordination from the top, will not produce significant, long-lasting benefits.

- Inmediatily start retraining the workforce and hiring new workers to fill talent gaps. Companies that 
have yet to focus on capability building will need to play catch-up to remain competitive.

- Capture value through rapid sprints, but manage the effort holistically with a long-term perspective.

By addressing these imperatives through a welldesigned and rigorous transformation program, companies can achieve rapid improvements that create value and motivate the entire organization to realize the vision of Industry 4.0.

It's clear that digital transformation isn't about reinventing the wheel. Rather, it's an opportunity to transform the purpose of that wheel to disrupt the way we do business in the digital economy.

And there is not a single solution for that.

\section{References}

1. S.Strambach, Knowledge-Intensive Business Services (KIBS) as drivers of multilevel knowledge dynamics, Int. J. Services Technology and Management, 10, 152-174 (2008)

2. ISO/IEC DIS 17025:2016

3. L. Lombardero, Trabajar en la era digital, LID Editorial Empresarial, (2015)

4. J.Rose, V. Lukic, T. Milon, A. Cappuzzo, Sprinting to Value in Industry 4.0, BCG Perspectives, (2016)

5. S. Scantlebury, J. Ross, W. Buariediel, Designing Digital Organizations, BCG Perspectives, (2016) 